\title{
The Effects of Co-Teaching Zones of Regulation on Elementary Students' Social, Emotional, and Academic Risk Behaviors
}

\author{
${\text { Marie Conklin }{ }^{1 *} \text {, Dharma Jairam }}^{2}$ \\ ${ }^{1}$ Morningside University \\ ${ }^{2}$ Fort Hays State University \\ *Corresponding author email: conklinm@morningside.edu
}

Received: 07 April 2021 / Accepted: 05 July 2021 / Published: 29 July 2021

\begin{abstract}
Student misbehavior is a significant concern in the current classroom. Teachers nationwide have implemented several approaches to reduce student misbehavior, including School-wide Positive Behavior Interventions and Supports (PBIS) and co-teaching. However, since misbehaver still disrupts learning, research is still needed to find a classroom intervention that will reduce misbehavior in a classroom to prevent students from under achieving, disruption of peers' learning and teacher burnout. Zones of Regulation focuses on self-regulation, while addressing sensory processing, executive functioning, and emotional regulation. This experimental study tested the effects of co-taught Zones of Regulation on students' Social, Academic, and Emotional Behavior Risk Screener (SAEBRS). Fiftysix early elementary students ( $48 \%$ female) were assigned randomly to either the experimental group, which received co-taught direct instruction with Zones of Regulation or the control group, which received standard instruction with a morning meeting. It was predicted that the experimental group would score higher on the SAEBRS than the control group. Although results showed no statistical difference on the SAEBRS scores between the two groups, more students in the experimental group moved from "at risk" to "not at risk". This study suggests additional research needs to be conducted to determine if co-taught Zones of Regulation instruction is an effective intervention for reducing misbehavior.
\end{abstract}

Keywords: Zones of Regulation, SAEBRS, school-wide intervention, risk behavior

\section{Introduction}

Student misbehavior is a significant concern in the current classroom (Ducharme \& Shecter, 2011). In the United States, approximately 3.5 million students were suspended during the 2011-2012 school year and nearly half of those students were suspended more than once (Robers et al., 2014). Furthermore, student misbehavior appears to be escalating. For example, $37.2 \%$ of schools in the United States had to take at least one serious disciplinary action for fighting, possession or distribution of an illegal drug, or possession or use of a weapon during the 2015-16 school year (Musu-Gillette et al., 2018). Nearly 70\% of public schools have at least one violent crime and $14.3 \%$ have 20 or more violent crimes per year (MusuGillette et al., 2018).

Schools have invested in various strategies both within the school and using resources in the community to address misbehavior (Cochran et al., 2014; Counts et al., 2018; Soave \& Koteskey, 2017). One of these resources includes a police officer assigned to patrol schools. In 2016, approximately $43 \%$ of schools in the United States had a police officer assigned to patrol the school (Counts et al., 2018; Soave \& Koteskey, 2017). However, many schools also have used their designated police officer to respond to discipline issues that were not criminal in nature (Counts et al., 2018). Cochran et al. (2014) reported that teachers spend an average of $40 \%$ of their day using strategies to reduce students' disruptive behavior. Fifty percent of teachers believe the strategies were ineffective (Cochran et al., 2014). According to Musu-Gillette 
et al. (2018), 43\% of teachers stated student misbehavior interfered with their teaching by taking up the teacher's time to deal with the misbehavior, rather than delivering instruction. Seventy percent of students reported their learning was disrupted by a peers' misbehavior in at least half of their classes (Department for Education, 2012). Several problem behaviors such as disruption, aggression and defiance disrupt the learning of both the student demonstrating the inappropriate behavior and their peers. (Algozzine et al., 2008; Alter et al., 2013; Finn et al., 2008; Harrison et al., 2012).

\subsection{Types of Misbehaviors in Schools}

Disruption, aggression, defiance and off task behaviors are common misbehaviors in the classroom (Algozzine et al., 2008; Harrison et al., 2012; Spaulding et al., 2010). Researchers show disruption is one of the top misbehaviors in the classroom (Algozzine et al., 2008; Harrison et al., 2012; Spaulding et al., 2010). Disruption includes any time a teacher stops teaching to correct a behavior (talking at inappropriate times, making noises, excessive talking or movement, silliness), but the misbehavior is not harmful or threatening (Algozzine et al., 2008; Harrison et al., 2012). Algozzine et al. (2008) reported that 49\% of the referrals in an elementary school of 502 students were for disruption. Spaulding et al. (2010) analyzed behavior discipline referrals from 1,510 schools and found disruption made up $20 \%$ of the referrals at the middle school level. When reviewing the misbehavior of over 3,600 students from 40 different states, Harrison et al. (2012) found over $20 \%$ of students were disruptive often or almost always in the classroom.

Aggression, defiance, and off-task behaviors were also consistent misbehaviors reported (Algozzine et al., 2008; Harrison et al., 2012; Spaulding et al., 2010). Harrison et al. (2012) reported about $30 \%$ of students were consistently off task. Spaulding et al. (2010) reported defiance as the biggest problem behavior across 1,510 different schools, with an average of $28 \%$ of referrals. Physical aggression made up $32.4 \%$ of the elementary referrals compared to $3.1 \%$ of high school referrals (Spaulding et al., 2010). Algozzine et al. (2008) also found $22 \%$ of referrals were for fighting and physical aggression.

\subsection{Consequences of Student Misbehavior}

Student misbehavior affects numerous individuals within the school (Arens et al., 2015; Brackett et al., 2011, Dalgic \& Bayhan, 2014; Finn et al., 2008). The negative outcomes begin at school and often continue long after the students leave school (Romi et al., 2015). Misbehavior also affects their peers and their associated learning outcomes (Arens et al., 2015; Bru, 2009). Finally, misbehavior affects teachers' stress and their ability to effectively teach all students (Bracket et al., 2011; Cochran et al., 2014).

\subsubsection{Students Who Misbehave}

Students who are disruptive in the classroom are more likely to have academic concerns, which include lower grades, retention, and drop out (Finn et al., 2008). Student misbehavior impacts a child's outcomes at school, as well as his or her future (Mallet, 2016; Romi et al., 2015). Students who consistently misbehave are more likely to end up in the juvenile court system (Mallett, 2016; Moffitt et al., 2011; Romi et al., 2015).

A study of 453 secondary students conducted by Bru (2009) found students who were disruptive in the classroom scored significantly lower in math $(M=39.6, S D=14.21)$ and English $(M=33.5, S D=$ 14.21) than their peers who were not disruptive in either math $(M=51.0, S D=16.36)$ or English $(M=$ $53.5, S D=16.36)$. The disruptive student's grade point average was also significantly lower $(M=2.65, S D$ $=0.70)$ than non-disruptive students $(M=3.67, S D=0.88)$ (Bru, 2009). Finn et al. (2008) found misbehaving eighth-grade students scored nearly ten points lower on their math and reading composite scores by tenth-grade. These students were also five times more likely to drop out of school and more likely to engage in illegal activity (Finn et al., 2008). In fact, 56\% of tenth grade students who were disruptive were using alcohol, and $27 \%$ of students were using marijuana (Finn et al., 2008). Students who were suspended or expelled were $8 \%$ more likely to drop out of school and $26 \%$ more likely be retained than 
students who were not (Fabelo et al., 2011). When consistently suspended or expelled, students do not receive their appropriate public education (Romi et al., 2015).

A rising concern is the school-to-prison pipeline (Romi et al., 2015). During the 2011-2012 school year there were about 3.5 million suspensions in the United States; however, only 433,800 incidents were for serious offenses such as physical aggression and use or possession of an illegal substance (Fabelo et al., 2011; Robers et al., 2014). In the last 30 years, there has been an increase in school suspensions for incidents that were not dangerous or illegal (Mallett, 2016). Some students have been suspended for persistent disrespect, not following directions, or disrupting the classroom (which could include yelling, talking too much, or horseplay) (Fabelo et al., 2011; Mallett, 2016). These persistent low-level offenses often cause students to end up in the juvenile court system, and once in the system, they struggle to get out (Moffitt et al., 2011; Romi et al., 2015).

\subsubsection{Effects of Student Misbehavior on Peers}

Misbehavior affects the students who are misbehaving and negatively impacts their peers (Hayling et al., 2008). The House of Commons Education Committee (2011) reported students lose an average of 30 minutes of instruction per day due to student misbehavior, which is equivalent to nearly three weeks of instruction every year. Hayling et al. (2008) found similar results, reporting teachers lost nearly 40 minutes per day due to disruption. Hayling et al. (2008) also found that schools with less than $10 \%$ of their day disrupted had $10 \%$ better achievement. When students disrupt the learning in a classroom, other students' academic achievement is at risk (Arens et al., 2015).

Arens et al. (2015) reported classrooms with higher levels of student misbehavior have lower achieving classrooms $(E S=-.414, S E=.050, p<.01)$. The effect size for individual students $(E S=-.331$, $S E=.015, p<.01)$ was less than the effect size of the whole class $(E S=-.414, S E=.050, p<.01)$ (Arens et al., 2015). Therefore, when students have peers who disrupt their classroom, their academic achievement is at risk (Arens et al., 2015).

Misbehaving students affect other students' ability to focus and to complete their work. Bru (2009) found that $60 \%$ of students stated they were unable to focus due to peers' disruptive behaviors. Forty percent of student stated that their classroom was too noisy to focus (Bru, 2009). When students are unable to attend to their work, their achievement decreases (Arens et al., 2015).

\subsubsection{Student Misbehavior Effects on Teachers}

Teachers' stress increases when working with students who consistently misbehave (Bracket et al., 2011). Teachers leave the profession early because of stress caused by student misbehavior (Alter et al., 2013; Brackett et al., 2011, Dalgic \& Bayhan, 2014; Ducharme \& Shecter, 2011). Many teachers state they do not feel equipped to manage on-going student disruptions. Seventy-five percent of these teachers also stated they felt much more effective with students who were not highly disruptive (Cochran et al., 2014).

When teachers deal with frequent misbehavior, they are unable to properly manage their class (Brackett et al., 2011). Ratcliff et al. (2010) described a cycle that often occurs in the classroom with student misbehavior. This cycle includes the student misbehaving, teacher reacts out of frustration, and student misbehaves again (Ratcliff et al., 2010). Principals observed 37\% of 34 different teachers engaging in this cycle (Ratcliff et al., 2010). Classrooms where this cycle occurs report having only $30 \%$ of students on task, whereas classrooms where this cycle did not occur, students were on task $74 \%$ of the time (Ratcliff et al., 2010).

Cochran et al (2014) surveyed 49 teachers who worked with students with highly disruptive behaviors in their classroom. Teachers were asked to share their frustration level and effectiveness in working with these students. Seventy-four percent of the teachers were either significantly or highly frustrated (Cochran et al., 2014). Since many teachers do not feel equipped to manage disruptive students, many interventions, strategies, and approaches are available to help teachers successfully work with students who are disruptive (Fallon et al., 2014; Horner et al., 2010). 


\subsection{Interventions to Address Student Misbehavior}

There are two commonly used interventions used to address misbehavior in the classrooms nationwide, including school-wide positive behavior interventions and supports (PBIS) and co-teaching (Horner et al., 2010; Friend, 2008). With both PBIS and co-teaching there have been some concerns with outcome measurements (Brandt et al., 2014) and implementation barriers (Friend, 2008). However, some researchers have found self-regulation interventions better equip students for school both behaviorally and academically (Raver et al., 2011; Wyman et al., 2010).

\subsubsection{Positive behavior interventions and supports (PBIS)}

A common evidence-based practice used in schools today to address misbehavior is School-wide Positive Behavior Interventions and Support (PBIS) (Horner et al., 2010). School-wide Positive Behavior Interventions and Supports is a three-tiered approach to providing behavior support. Tier one is a schoolwide intervention that includes teaching expected behavior, collecting data about the school-wide behavior, and providing logical consequences when students do not follow the expected behavior. This tier is expected to work for $80 \%$ of the student body (Ogulmus \& Vuran, 2016). Horner et al. (2010) explain that students receive additional instruction and reinforcement on the expected behavior in tier two. Tier two supports are typically for approximately $15-20 \%$ of students (Ogulmus \& Vuran, 2016). Tier three is for about $5 \%$ of the school population and consists of individual student interventions (Horner et al., 2010; Ogulmus \& Vuran, 2016). When using PBIS, the school discipline data, including discipline referrals, attendance data, and suspension rates, is routinely reviewed and changes are made accordingly to provide all students with the proper supports (Horner et al., 2010).

A study by Nocera et al. (2014), showed that after beginning PBIS in their school, a 36\% drop occurred in their Office Discipline Referral (ODR) over three school years. Within the ODRs a 49\% decrease in disruptive behaviors occurred (Nocera et al., 2014). Nocera et al. (2014) also found a 39\% drop in total suspensions after using PBIS.

Bradshaw et al. (2010) also found a significant decrease in ODRs and suspensions after using SWPIBS. The percentage of ODRs dropped from 18.8\% to $18.1 \%$ (Wilks's $\Lambda=.67, \mathrm{~F}(1,14)=6.99, p=$ $\left..019, \eta^{2}=.33, d=.08\right)$. In addition, the number of ODRs per student reduced significantly after using PBIS (Wilk's $\Lambda=.52, F(1,14)=12.90, p=.003, \eta^{2}=.48, d=.12$ ). This study reported that suspensions were significantly reduced in the PBIS school $(Z=-2.17, p=.03)$ but not the comparison schools $(Z=-1.54, p$ $=.12$ ), (Bradshaw et al., 2010). In addition to suspensions and ODRs, Bradshaw et al. (2010) found fifth grade demonstrated greater gains in math than the comparison school, but these gains were not significant ( $t=-1.67, d f=35, p=.105, d=.54)$. However, Bradshaw et al. (2010) found no difference in achievement in fifth grade reading or third grade reading and math.

\subsubsection{PBIS implementation concerns}

The most common way to measure PBIS's effectiveness is through tracking office discipline referrals (ODR) (Brandt et al., 2014). Even though there is often a decrease in ODRs when a school uses PBIS, the cause of this decrease is not always known (Brandt et al., 2014). Sometimes the cause is not due to reduced misbehavior, but instead a change in the behavior policy in a school (Brandt et al., 2014). Even though ODRs track types of misbehavior and time of occurrence, the information fails to show if students have learned the expected behaviors (Brandt et al., 2014). Sometimes schools see an increase in ODRs after implementation because teachers did not know what behaviors constituted an ODR and what did not (Brandt et al., 2014). Another measure of misbehavior schools has used is suspensions (Brandt et al., 2014).

Similar to ODRs, suspensions do not provide information on whether or not students have learned the expected behaviors (Brandt et al., 2014). A decrease in suspensions when using PBIS does not mean the school will have fewer suspensions than non-PBIS schools (Bradshaw et al., 2010). Even though the 
percentage of students suspended decreased by $25 \%$, the school implementing PBIS still had nearly twice as many students who were suspended as the comparison school (Bradshaw et al., 2010).

In addition to having poor effectiveness measures, the PBIS implementation is sometimes met with hesitation and inconsistency (Fallon et al., 2014). Fallon et al. (2014) surveyed 172 teachers from ten different kindergarten through twelfth-grade schools who were using PBIS. When asked 12 questions about procedures, instruction, and classroom success, $50 \%$ of teachers stated using procedures for expected behaviors aligned with school-wide procedures was challenging (Fallon et al., 2014). These challenges include concerns about implementation fidelity by all staff and philosophical disagreements about reinforcement (Tyre \& Feuerborn, 2017). Fallon et al. (2014) reported that providing consistent consequences for problem behaviors was challenging for 50\% to 60\% of these teachers (Fallon et al., 2104). The school-wide evaluation tool can be used to determine if PBIS components are being used, but some schools choose not to use it because of time constraints (Brandt et al., 2014).

\subsubsection{Co-teaching Intervention}

Teachers often feel undertrained to work with students who misbehave regularly (Cochran et al, 2014). One way to address this concern is by having a highly qualified special education teacher co-teach with the general education teacher to address misbehavior in the classroom (Barron et al, 2019; Strogilos \& Avramidis, 2016). Co-teaching is when two or more professionals provide instruction to a group of students (Hang \& Rabren, 2009; Murawski \& Hughes, 2009). Often during co-teaching, one teacher can teach, while the other monitors and addresses student misbehavior (King-Sears et al., 2014; Strogilos \& Avramidis, 2016). Strogilos \& Avramidis (2016) showed that students who received co-teaching instruction had fewer misbehavior incidents in the classroom than students who did not, $t(21)=-5.46, p<.001$.

Another study by King-Sears et al. (2014) asked seven students in one co-taught classroom various questions about the co-teaching environment. Seventy-one percent of the students believed behavior was better in their co-taught classroom (King-Sears et al., 2014). In addition, more consistent behavior management strategies were used to prevent misbehavior from occurring (Martinez et al., 2016). Coteaching reduced high risk behavior such as physical aggression, both in the classroom $(b=-.47, S E=.06$, $p<.001)$ and school-wide $(b=-.49, S E=.06, p<.001)$ level (Martinez et al., 2016).

Hayling et al. (2008) state that actively engaged students were more likely to learn. Actively engaged is defined as participating in the current learning task, while following directions, school rules, and classroom expectations (Hayling et al., 2008; Strogilos \& Avramidis, 2016). After completing 264 classroom observations in 22 different classes, Strogilos \& Avramidis (2016) found that students who were in a cotaught classroom were more actively engaged than in classrooms with only one teacher $(t(20)=4.15$, $p<.001)$.

Hang \& Rabren (2009) examined seven different schools that included 31 general education and 14 special education teachers who used co-teaching. Students who received co-teaching scored significantly higher $(t(30)=6.97, p<.001)$ in reading and math on their national curve equivalents than the year they did not receive co-teaching $(t(30)=2.96, p .01)$ (Hang \& Rabren, 2009).

Another advantage to co-teaching is one teacher can provide additional instruction to students who did not understand a concept (Murawski \& Hughes, 2009). Co-teaching provides opportunities for more intensive interventions for students who may need additional support with concepts or skills (Murawski \& Hughes, 2009). For example, one teacher could provide an additional lesson or present the information in a different format for students who do not understand a concept, while the other teacher continues to work with the other students (Murawski \& Hughes, 2009; Sweigart \& Landrum, 2015). Students in a co-taught classroom were three times more likely to receive small group instruction and twice as likely to receive one-on-one instruction compared to those students in a single-teacher classroom (Sweigart \& Landrum, 2015). Although co-teaching has shown potential for positive outcomes for students, concerns about effective implementation still linger (Friend, 2008). 


\subsubsection{Barriers to co-teaching}

Three barriers cause co-teaching implementation to be less effective (Friend, 2008; Jackson et al., 2017). One barrier is a lack of resources (Chitiyo, 2017). These resources can include co-planning time, professional development, and the cost of the second teacher (Chitiyo, 2017; Friend, 2008; Jackson et al., 2017). Co-planning time is crucial for effective co-teaching implementation (Friend, 2008; Jackson et al., 2017). Both teachers need co-planning to be prepared for the lesson and provide the same support, both academically and behaviorally, to every child (Chitiyo, 2017; Friend, 2008). Chitiyo (2017) found that when surveying 77 teachers, kindergarten through twelfth grade, $62 \%$ stated they did not have the proper skills to effectively co-teach. In addition, only $44 \%$ of these teachers had received professional learning on coteaching from their university coursework, the remaining $56 \%$ received short-term professional learning, such as a conference or reading a professional article (Chitiyo, 2017). Inconsistent training can lead to conflict about instructional decisions and responsibilities (Chitiyo, 2017).

Another barrier to effective co-teaching is when the two co-teachers do not have a positive relationship (Friend, 2008). Chitiyo (2017) found that 21\% of teachers did not support co-teaching. Teachers may not want to share instructional responsibilities or their philosophical differences, such as how to respond to a misbehavior or what the student should be required to complete (Chitiyo, 2017). Teachers need to work together because flexibility, compromising, and a shared commitment are important when co-teaching (Chitiyo, 2017; Friend, 2008).

The final potential barrier is lack of administrative support. Some principals do not understand or see value in co-teaching and do not provide time for co-planning or training (Friend, 2008). According to Hang \& Rabren (2009), 100\% of teachers who co-taught needed co-planning time for the success of coteaching. To provide the best model for co-teaching, all components should be considered when implementing (Friend, 2008).

When teaching a student to change their behavior, it is important to teach the desired behavior to replace the undesired behavior (Liew, 2011). One reason a student may be misbehaving is because they lack self-regulation skills (Liew, 2011). Without these skills, many of the day-to-day functions in the classroom are difficult or impossible for students to accomplish independently (Duncan et al., 2017). Self-regulation cannot be learned by the child alone but requires the modeling and teaching from adults around the child (Perez, 2011; Woltering \& Shi, 2016).

\subsection{Teaching Self-Regulation Skills}

Self-regulation is the ability to change your behavior to adapt to an environment (Kuypers, 2011). To adapt to an environment, one may need to regulate their sensory needs, their emotions or their impulses so they can appropriately engage in the designated environment (Kuypers, 2011). Kuypers (2011) states three neurological components need to be addressed when becoming regulated. They include sensory processing, executive functioning and emotional regulation. When students self-regulate, they can make better decisions and appropriately participate in the classroom (Kuypers, 2011).

Raver et al (2011) conducted a study of 467 preschool students. The students who participated in a classroom wide self-regulation intervention showed a statistically significant difference from the control group in attention and impulse control $(E S=-.43, S E=.0 .09, p<.05)$, executive function $(E S=-.37, S E$ $=.13, p<.05)$ as well as the pre academic skills of vocabulary $(E S=-.34, S E=.60, p<.05)$, letter naming $(E S=-.63, S E=.05, p<.01)$, and early math skills $(E S=-.54, S E=.51, p<.01)$ (Raver et al., 2011).

When students were taught self-regulation skills in the classroom, they were more likely to participate in class rather than misbehave (Wyman et al., 2010). Wyman et al. (2010) conducted a study with 226 kindergarten through third-grade students. The students who received self-regulation skills instruction had significantly better behavior control than the control group $(t(224)=2.26, p=<.03)$ after the intervention (Wyman et al., 2010). 


\subsubsection{Zones of Regulation}

The Zones of Regulation (ZoR) is a curriculum used to teach students how to self-regulate by using calming, thinking and problem-solving strategies. Students who disrupted the classroom by making noises, refusing to work, hurting others or yelling, did not seem motivated to change their behavior (Kuypers, 2011). Kuypers (2011) suggested these students might not have known how to change their behavior. Three phases of lessons focus on self-regulation while addressing sensory processing, executive functioning and emotional regulation (Kuypers, 2011).

During phase one, students learn how to recognize their emotional state and determine whether or not they are in a state that is "ready to learn" (Kuypers, 2011). Ready to learm is when a student is free of distractions and focused only on the current learning task (Kuypers, 2011). When students are in a state where they are ready to learn, they are actively engaged. Just as Strogilos \& Avramidis (2016) pointed out, when students are more actively engaged, misbehavior is less likely in the classroom.

Kuypers (2011) explains the way someone feels or their level of alertness can be categorized into one of four zones: blue, green, yellow and red. In addition to emotions, these zones also categorize physical sensations such as relaxation or tension. Traffic signs represent these zones. When in the blue zone, the student may feel tired or sick. Students may have their head down on their desk. When in the blue zone, a student typically needs some rest or refueling (rest area sign). When in the green zone, this means ready to learn. Students may feel content, proud, or relaxed. The green zone is represented by a green light. The yellow zone means a student is at a heightened state of alertness and has more energy. A student is typically tense and filled with emotions such as frustration, annoyance or excitement. When in the yellow zone, caution is warranted and a calming strategy may be necessary. A yellow caution sign represents the yellow zone. Red zone means the student is out of control and the current behavior needs to stop. The red zone is represented with a stop sign. The traffic sign may help students know what they may need in a specific zone (Kuypers, 2011).

During phase two, students are taught several strategies. Students are resented with a variety of sensory, calming, thinking, and problem-solving strategies. Numerous strategies are taught and practiced throughout the lessons. Then the students reflect during each lesson on which strategies calm them down (a yellow or red zone strategy) and which strategies help to give them more energy (a blue zone strategy) (Kuypers, 2011). This information is later used to help the students create their won person 'toolbox' to help them regulate (Kuypers, 2011).

During phase three, students create an individualized 'toolbox' where they identify which strategies work for them so they can be ready to learn throughout the day. In addition, students learn when they should use each strategy. For example, students learn they should use their calming strategies immediately after realizing they are in the yellow zone, to prevent themselves from being in the red zone. The goal is for students to use the appropriate strategies rather than choose to misbehave (Kuypers, 2011).

\subsubsection{Teachers' role throughout each phase of ZoR}

While teaching Zones of Regulation, teachers are encouraged to not only teach the lessons but also use consistent vocabulary to identify emotions and model potential calming, thinking and problem-solving strategies throughout the day (Kuypers, 2011). As students learn each phase, the teacher may prompt them. For example, if a student is frustrated with a task and does not use a strategy, the teacher may say, "I noticed your fists are clenched and you are frustrated. Remember, that means you are in the yellow zone. What tool do you think you might use?" However, if students identify they are in the yellow zone but have not yet identified a tool that works for them, the teacher may provide options at the moment for students to try. When the students are still in control, they may be prompted to use their folder, where all their strategies are kept. These steps are used if a student is struggling to use the strategies in the moment (Kuypers, 2011).

When teaching Zones of Regulation, students learn how to identify their behavior and whether or not it matches their environment. The learn identify how their behavior affects others around them. When their behavior does not match their environment, they are dysregulated and need to use a tool to help them 
The Effects of Co-Teaching Zones of Regulation on Elementary Students' Social, Emotional, and Academic Risk Behaviors

get regulated. Sometimes they may need a tool to calm them down, while other times they need a tool to give them more energy. When students are aware of the potential tools they can use, the goal is for student sot use their tools rather than misbehave (Kuypers, 2011). However, there is no current research on whether Zones of Regulation is an effective class-wide intervention for reducing misbehavior.
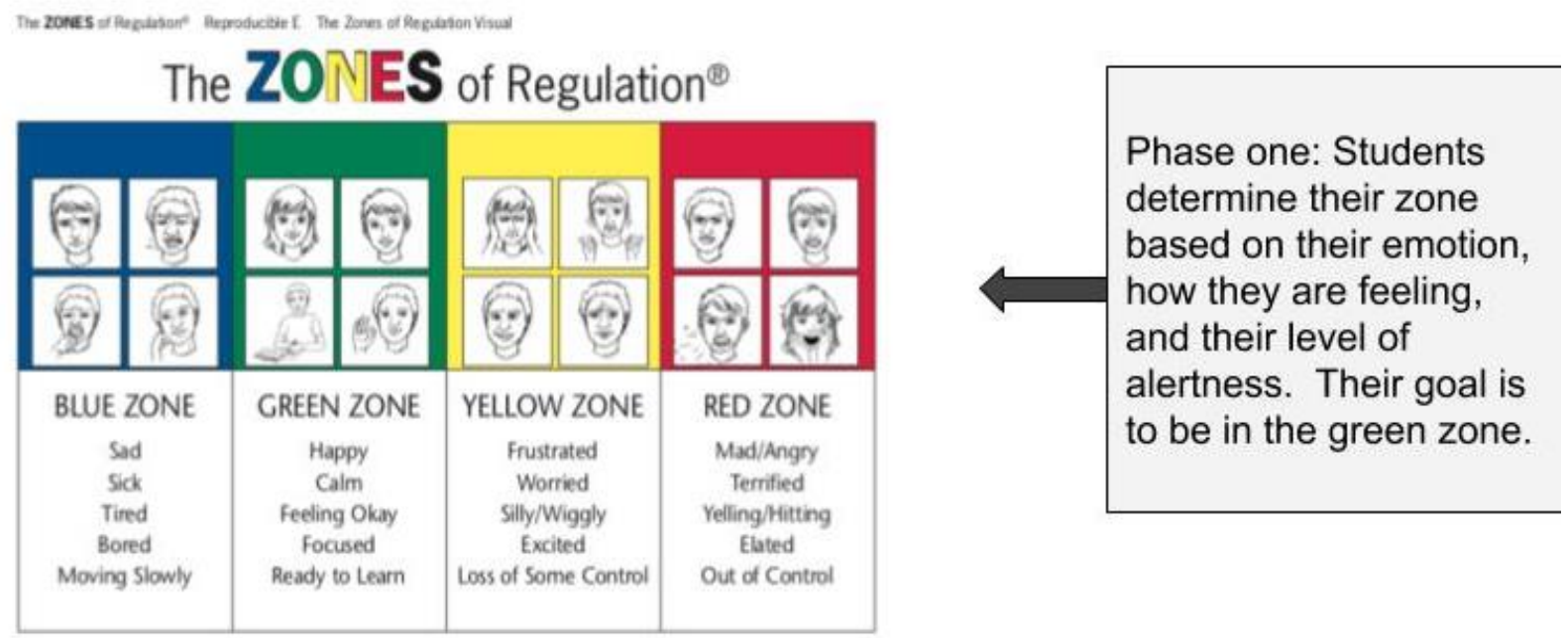

Name:

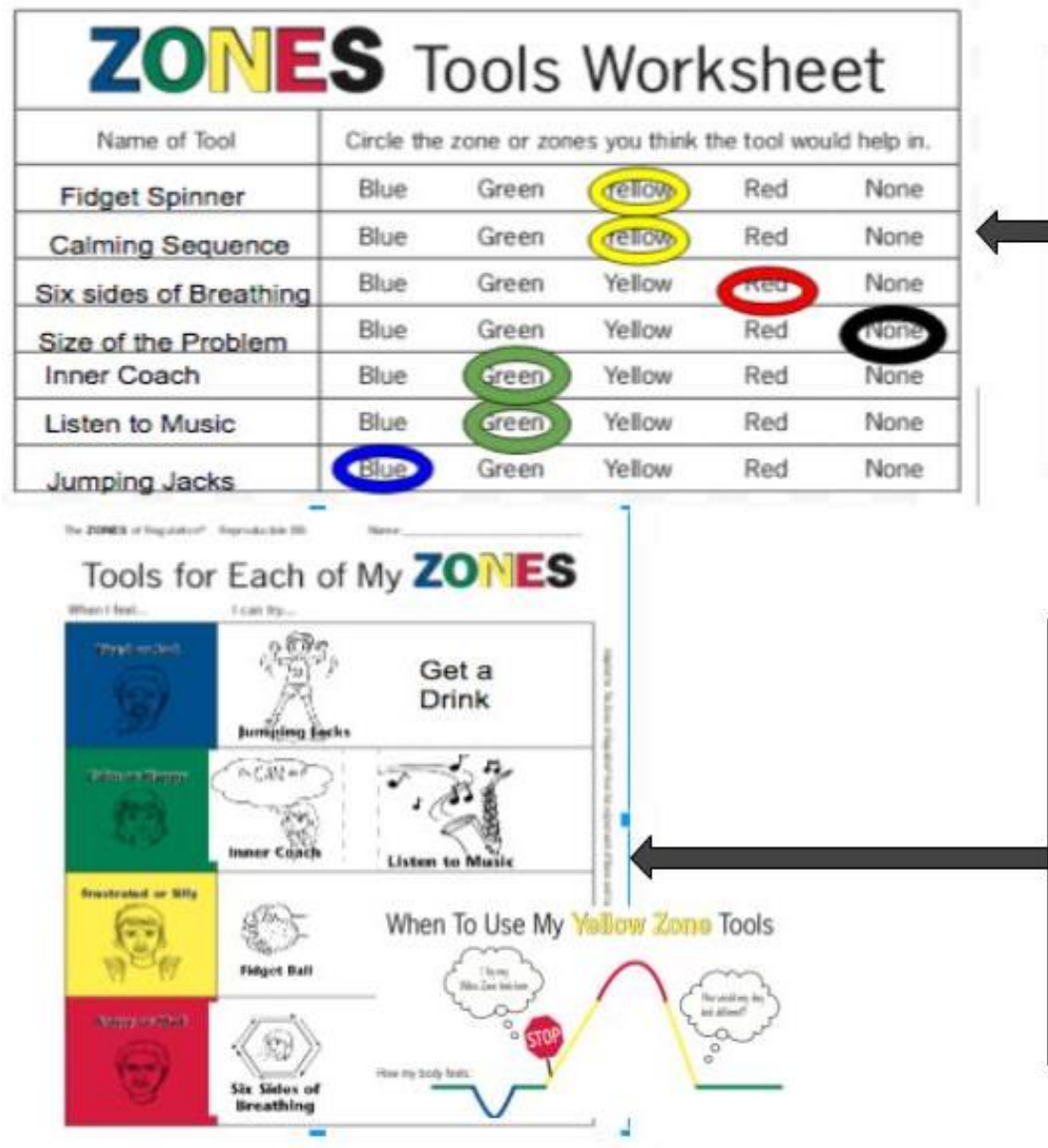

Phase two: Students are taught various strategies and practice them. They then reflect on which strategies may or may not be helpful in each zone.

Figure 1. The three phases of learning that occur during the Zones of Regulation instruction. 


\subsection{Theoretical Framework}

Zimmerman's self-regulated learning theory (1990) states that when people are provided with various strategies, each individual will try various strategies and determine which strategy works for them to obtain their goal. This theoretical framework is aligned with Kuypers' (2011), Zones of Regulation. The goal for students in the classroom is to be focused and engaged so they can learn (Kuypers, 2011). When students are not engaged or their behavior does not match the environment, they need to determine which strategy will help them get them back on task (Kuypers, 2011). Students are provided various types of strategies (thinking, problem solving, and calming) to use when their behavior is not expected in their current environment (Kuypers, 2011). For example, if someone is distracting them, they may choose to use a thinking strategy to help them focus and ignore the other student or calmly ask them to stop. However, if they are at a birthday party and just sitting in a corner, they may need a strategy to help give them more energy so they can enjoy the birthday party. When students choose the correct strategies, they are appropriately engaged in their environment. In school if they are appropriately engaged in the classroom, they are less likely to misbehave (Hayling et al., 2008)

\subsubsection{Self-regulated learning features}

Three major features make up self-regulated learning (Zimmerman, 1990). The theoretical framework of Zimmerman's (1990) theory is aligned with the three phases of Zones of Regulation. First, students become self-regulated learners by learning various strategies that can be used to process, respond, or reach a goal; they use these strategies to learn new skills. The goal in Zones of Regulation is to be engaged in their learning (green zone) see figure 1 for how this feature aligns with Zones of Regulation (phase one and two). Self-regulated learners think about how these strategies can best help them to work toward a specific outcome.

Second, self-regulated learners use their own feedback to monitor the strategy's effectiveness. Students will use strategies that work to get the desired outcome. However, students will search for another more effective strategy if their strategy does not work. Phase two in figure 1 describes this feature in Zones of Regulation.

Third, self-regulated learners identify how to use the chosen skill and identify why a skill works to help reach the desired outcome (Zimmerman, 1990). Phase three in figure 1 explains this feature in Zones of Regulation. Self-regulated learners continuously seek strategies so they can be at their best to learn (Zimmerman, 1990; Zimmerman, 2002).

\subsubsection{Empirical Support of Self-Regulated Learning}

To test the self-regulated learning theory, Zimmerman \& Martinez-Pons (1986) randomly interviewed 40 low achieving and 40 high achieving students. The number of self-regulated strategies students reported using predicted whether they were low achieving or high achieving $93 \%$ of the time. High achieving students used self-regulated learning strategies two to five times more often than lower achieving students (Zimmerman \& Martinez-Pons, 1986). These strategies included keeping records and monitoring, self-consequences, and environmental structuring (Zimmerman \& Martinez-Pons, 1986).

More recently, Ning \& Downing (2015) conducted a study of 838 college students who used varying levels of self-regulated learning strategies. There are two main types of self-regulation, which include cognitive and behavior. Cognitive strategies include self-testing and study aids. Behavior regulation strategies include time management and concentration. Ning \& Downing (2015), studied four groups of students. Group one used a combination of cognitive self-regulation strategies and behavior-oriented strategies. Group two used only cognitive-oriented self-regulated learning strategies, group three used only, behavioral-oriented self-regulation strategies, and group four used very few or no self-regulation strategies (Ning \& Downing, 2015).

The students who used a combination of behavior oriented and cognitive self-regulated learning strategies were twice as motivated to learn $(M=3.99, S D=.93)$ compared to students who used only a few 
The Effects of Co-Teaching Zones of Regulation on Elementary Students' Social, Emotional, and Academic Risk Behaviors

self-regulated learning strategies $(M=2.12, S D=.89)$. Students who used a variety of strategies also had a higher grade point average $(M=3.18, S D=.35)$ than the group who used fewer self-regulated learning strategies $(M=2.85, S D=.37)$. An ANOVA test confirmed that students who were self-regulated learners were statistically more motivated $(F(4,827)=176.28, p<.001)$ and had a higher GPA $(F(4,827)=35.92$, $p<.001)$ (Ning \& Downing, 2015). Teaching students how to self-regulate may be the key to reducing misbehavior in the classroom (Kuypers, 2011). Further research is necessary to determine the best approach to reduce misbehavior.

\subsection{Purpose of this Study}

Misbehavior continues a major concern in the classroom (Ducharme \& Shecter, 2011). Numerous strategies have been tried, including suspensions, police officers patrolling schools to deal with misbehavior, and School-wide Positive Behavior Interventions and Supports (PBIS). Suspensions and a school resource officer have not been shown effective for reducing misbehavior (Counts et al., 2018; Mallett, 2016). In addition, there are barriers that lead to ineffective co-teaching and providing a second teacher in the classroom is not always a resource that can be funded (Friend, 2008). Although PBIS has been effective for reducing some misbehavior (Bradshaw et al., 2010; Nocera et al., 2014), there are concerns as to whether or not student are learning the appropriate behavior (Brandt et al., 2014). Therefore, more research is necessary to find a classwide intervention to reduce misbehavior in the classroom.

Currently, research is lacking on whether or not the Zones of Regulation curriculum is an effective classwide intervention at the elementary level. There is also a lack of research on the relationship between a co-taught self-regulation curriculum and risk for social, academic, and emotional behavior. This study examined the effects of co-teaching Zones of Regulation on second-grade students' behavioral and emotional risk. The hypothesis was that second-grade students who received co-taught direct instruction using the Zones of Regulation curriculum would score higher on the Social, Academic and Emotional Behavior Risk Screener (SAEBRS) than students who did not receive direct instruction using Zones of Regulation.

\section{Methodology}

\subsection{Participants}

Ninety-seven second grade students from a rural district in the Midwestern United States were divided into four classrooms at the end of the 2017-2018 school year. Female teachers were assigned to the four classrooms. Two teachers were within their first five years of teaching and two teachers had taught for more than 10 years. The first-grade teachers from the previous year used special education services, title services, and the check-in check-out intervention to determine where to place students in the appropriate class so that various services were balanced. In addition, teachers used behavioral observations regarding social behavior between students to best determine which students to put in each classroom. The classroom assigned to be the experimental group contained the most students in second-grade who were at risk in at least one category in the social, academic, and emotional behavior risk screener (SAEBRS). The control group consisted of second grade students who were not in special education, did not receive any Zones of Regulation teaching, and did not score a perfect score on the pre-test. All special education students were removed from the study because there were no special education students in the experimental group. The final 56 students ( $48 \%$ female) consisted of 33 students in the control group and 23 students in the experimental group.

The students were all 7- and 8- years old and attended a school where $65 \%$ of the students received free and reduced lunch. In the control group, there were 12\% African American, 76\% Caucasian, 6\% biracial, and 6\% Asian students. In the experimental group, there were 26\% African American, 61\% Caucasian, $9 \%$ bi-racial, and 4\% Asian students. The students did not receive any incentive for participating in this experiment. 


\subsection{Materials}

\subsubsection{Curriculum: Zones of Regulation}

The book Zones of Regulation: A Curriculum Designed to Foster Self-Regulation and Emotional Control (Zones Regulation) was used to teach 24 lessons. The first 12 lessons focus on the structure the Zones Regulation and how to identify each zone. Students learned how to first identify feelings using people in books and pictures. Students were provided with a blue, green, yellow and red colored craft stick to indicate their current zone. The recommended books in the curriculum were used. They include On Monday When it Rained by Cheryl Kachenmeister, Miss Nelson is Missing by Harry Allard and James Marshall, and Do I Feel? An Interactive Reading Book of Emotions by Joan Green. During lessons containing books read aloud, the texts were projected using an Epson PowerLite 83+ projector and an Elmo document camera. Pictures used during instruction came from the curriculum and were of faces showing various feelings including sad, depressed, proud and frustrated. Posters were also created for the first lesson to use along with the pictures. The movie clip used in "The Zones in Video" lesson was The Incredibles video (https://www.youtube.com/watch?v=2okrVHFKOoA) and the TEAM from "You're a Good Man, Charlie Brown" (https://www.youtube.com/watch?v=C3LazuRx6Eo). In the lesson "Me in My Zones," a Samsung Galaxy S9 was used to take pictures of the students in their zones. These pictures were then printed in color for students to cut out and paste into their books. The sensory items used in the "Exploring Sensory Support Tools" lesson included a stress ball, a marble fidget, an infinity cube, a soft key-chain, a fidget spinner, a fidget chain, a magic snake, scented wax, silly putty, two magnets, a fidget rolling pin, a pea pod fidget, and various squishy fidget shapes. During the lesson "Superflex Versus Rock Brain," an actual rock, approximately four inches in diameter, was used rather than duct tape. Students were provided a Zones of Regulation folder that they carried throughout the day. In the folder, the students kept their reproducible, which included activity pages, strategy explanations for the students, tool awards for the last lesson, and picture cards of emotions and tools. These were used for each lesson as designated in the curriculum and printed in color.

\subsubsection{Social, Academic, and Emotional Behavior Risk Screener}

The teachers completed a Social, Academic, and Emotional Behavior Risk Screener (SAEBRS) on FastBridge for each individual student. The teachers used a MacBook Pro OS X 10.9.4 with 8GB of RAM, 2.9 Intel Core 17 operating system and Intel HD Graphics 4000 to complete the SAEBRS. A Likert scale (Never, Sometimes, Often, and Almost Always) was used on 19 different items that were entered into Fastbridge (fastbridge.org) to provide four scores, including: a) social, b) academic, c) emotional behavior, and d) a total behavior score. An example statement in the social behavior section is "student uses polite and socially appropriate responses towards others." In the academic behavior section, an example is "Students shows interest in academic topics." In the emotional behavior section "Student has difficulty rebounding from setbacks." is another example (See Appendix A for full SAEBRS exam).

After all the statements were rated, a raw score determined if students were at risk or not at risk. The benchmark for at-risk remained the same throughout the school year. To be considered at risk for social, emotional, academic or total behavior a student must score below 13, 10, 18 and 37 respectively. One recent study by Kilgus et al. (2016) examined two different samples where SAEBRS was used as the indicator. Kilgus et al. (2016) confirmed previous studies finding SAEBRS reliable (Cronbach's alpha range in .83-.93 at the elementary level and .82-.94 at the middle school level) in determining risk outcomes (Kilgus et al., 2016).

\subsection{Procedure}

This study was a quasi-experimental between-group study design. The students' SAEBRS baseline scores were from the spring of 2018 by the students' first-grade teachers. The 2018-19 second-grade homeroom teachers completed the SAEBRS in the fall two weeks after the completion of the intervention. 
The independent variable was the Zones of Regulation class-wide intervention. The dependent variable was the students' SAEBRS scores, which indicates students' behavioral and emotional risk.

\subsubsection{Instruction for all second-grade students}

Both the experimental and control groups received a 30-minute lesson once a week from the school counselor on social-emotional learning. During this experiment, lessons were on problem-solving skills from the Kelso's Choice curriculum. These lessons included expectations during guidance, Kelso's choice big and small problems, two lessons on Kelso's different choices for solving problems, and five lessons on how to properly use each choice. Every student in second grade participated in these lessons.

\subsubsection{Morning Meeting}

The control group participated in an activity called morning meeting. The goal of morning meeting is to provide students an opportunity to interact with their peers so they can learn proper social skills (Boyd \& Smyntek-Gworek, 2012; Gardner, 2012). Gardner (2012) also states that providing a morning meeting builds classroom community. Boyd \& Smyntek-Gworek (2012), also explain morning meeting as an opportunity to allow the students to properly transition from home to school. Students are provided an opportunity to share about their lives and be heard (Boyd \& Smyntek-Gworek, 2012). Providing this opportunity for students provides them a time to discuss any concerns they may have that could distract them from learning (Boyd \& Smyntek-Gworek, 2012). The morning meeting included a greeting, sharing, group activity which involved some sort of team building, and morning message (Gardner, 2012).

When they students arrived at school, they came in each day and gathered at the carpet. Students greeted one another in various ways, assuring every student directly greeted at least one person. Next, the students could share about events going on in their lives. Then the students participated in an activity that requires team building and problem-solving. Finally, the students read the morning message that was written by their teacher before the day began.

\subsection{Zones of Regulation Intervention}

Before any lessons began, the co-teachers created a folder for each child to keep all their Zones of Regulation materials. In addition, each child received a color craft stick for each zone (red, blue, green and yellow). These sticks were used randomly throughout the lessons and the remainder of the day to determine if students could properly identify their current zone.

Every lesson was co-taught, and the co-teachers met once a week to plan. Co-teaching included the two teachers alternating between taking the lead on a lesson while the other teacher added to the discussion and the lesson throughout. Each lesson was taught according to the Zones of Regulation curriculum. Each lesson included a lead-in, an activity (sometimes there were variations for different age groups), and a wrap-up (See Appendix B).

\subsubsection{Lead in}

For each lesson, the teachers determined who would lead each part of the lesson. The students were asked a question to start thinking about the lesson, followed by a statement about the purpose of the lesson. The students either sat in a circle or in rows depending on if the lesson had more discussion (circle) or more activities that required the document camera and projector (rows). One example of a question during the lead in includes, "Why is it important to know what someone's facial expression means?" The students completed the lead-in with the lead teacher through discussion.

\subsubsection{Activities for different age groups}

After the lead-in, there were two options for the activity section; to be consistent, the lesson intended for younger students was taught. The activity section included an activity where the students practiced the skill they were focusing on. The teacher modeled the activity at the carpet. The students then 
completed the activity at their table spots. While the students were working on their activity, the teachers circulated the room and helped students who had questions.

\subsubsection{Wrap-up}

When students completed the activity, they read quietly while peers finished. When all students were done, the class returned to the carpet to complete the wrap-up. Discussion questions about the lesson were then asked. "Can you recognize what zone students or teachers are in by their facial expressions?" is one example of a wrap-up question. Various students shared out during the wrap-up. The teacher ended each lesson encouraging students to practice the new skill throughout the day and sharing with the students what they would be learning the following lesson.

\subsubsection{Exit ticket}

The lesson ended with an exit ticket completed by the students to determine if they understood the skills/concepts to learn the next lesson. If less than five students did not understand a concept at the end of the lesson, one teacher provided an additional 15-minute booster lesson using the additional activities in the curriculum. Later the same day, a small group lesson was taught to reteach the qualifying students. If more than five students did not understand a concept, the whole class received a re-teaching lesson, using the additional activities in the curriculum.

\subsubsection{Generalized learning}

The ways to generalize the lesson were reviewed during each planning session. Generalizations applicable to the classroom were applied. For example, in lesson one (see Appendix B) it states to hang posters in the common areas. Since not all students in the school were receiving Zones of Regulation, the teacher displayed the posters in the classroom.

\subsubsection{Schedule of lessons}

Students in the control group started their morning meeting on the first day of school. These meetings occurred every day. Students in the control group did not receive any Zones of Regulation instruction during the first five days of school. This provided time for the homeroom teacher to teach classroom expectations and procedures. However, the co-teacher went into the classroom each day at the designated time to begin building relationships with the students. On the sixth day of school, the first lesson was taught.

During the first 12 lessons (phase one), the students learned how to categorize feelings into the four colored zones: blue, green yellow and red. Students then learned how to identify those feelings and zones in themselves by making books with pictures of themselves in the different zones. They tracked how their zone changed throughout the day and what affected their zone. Finally, they learned what triggers might cause their zone to change.

In the following six lessons (phase two), students learned about different strategies (tools) they could use when dysregulated (not in the green zone). Students explored various sensory tools, breathing tools, and thinking tools. After lesson 12, each student identified what zone they were in at least two times a day. Students indicated their zone by holding up the proper color craft stick correlated to their current zone.

During the final six lessons (phase three) students identified proper tools for their own personal toolbox. They tracked their tool usage over time and determined the best time to use each tool. During the final lesson, teachers observed students using their tools throughout the day. Students earned a "tool reward" when they used their tools. This reward was a slip of paper that said "tool reward" on it. The teacher continued to ask the whole class at least twice a day at random times to identify their zone by holding up the proper color craft stick correlated to their current zone.

After lesson 24 a two-week period occurred where the teacher continued to model and support students by using Zones of Regulation language and strategies throughout the day. The teacher continued 
the twice a day zone check. Two weeks after the lessons were complete, the teachers completed the SAEBRS again for each child.

\subsection{Data Analysis}

The purpose of this study was to determine if teaching the curriculum Zones of Regulation would improve a student's risk score on the Social, Academic and Emotional Behavior Risk Screener (SAEBRS). After the intervention, teachers completed the SAEBRS to determine if student scores increased. Four independent sample $t$-tests of SAEBRS were run for the control group and experimental group for each sub-score and total score to determine if students in the experimental group. The pre-test scores were from Spring of 2018 and post-test scores were from Fall of 2018. In addition, the scores were compared with the at-risk scores to determine if any scores were above the at-risk cut off for each category. Finally, individual scores were reviewed to determine if any students were no longer at risk after the intervention. The hypothesis for this experiment was that the experimental group would score higher on the SAEBRS than the control group on the SAEBRS.

\section{Results}

The purpose of this study was to determine if students who received co-taught direct instruction using Zones of Regulation scored higher on the SAEBRS than students who did not receive the instruction. The SAEBRS scores for both groups were used for the pre- and post-test. The social, academic, emotional, and total risk score and were analyzed. An alpha level of .05 was used for all statistical tests. Results did not support the hypothesis that students who received co-taught direct instruction using the Zones of Regulation curriculum would score higher on the SAEBRS than those who did not receive the same direct instruction.

The $t$-tests for the pre-tests showed that both groups scored statistically similar for the total score $(t(54)=1.35, p=.18)$, social score $(t(54)=1.39, p=.17)$, emotional score $(t(54)=0.52, p=.60)$, and academic score $(t(54)=1.90, p=.06)$. See Table 1 below for all pre-test $t$-test results.

Table 1. Results from Independent Samples T-tests for Pre-Test Scores

\begin{tabular}{lcccc}
\hline & $t$ & $d f$ & $p$ & Cohen's $d$ \\
\hline Total & -0.37 & 54.00 & 0.70 & -0.11 \\
Academic & -1.57 & 54.00 & 0.12 & -0.43 \\
Social & -0.29 & 54.00 & 0.77 & -0.08 \\
Emotional & 1.85 & 54.00 & 0.07 & 0.50 \\
\hline
\end{tabular}

Table 2. Means and Standard Deviations for Pre-test

\begin{tabular}{lllcc}
\hline & Group & N & Mean & SD \\
\hline Total & 1 & 33 & 46.18 & 9.51 \\
\multirow{3}{*}{ Social } & 2 & 23 & 42.26 & 12.17 \\
& 1 & 33 & 14.73 & 3.25 \\
Academic & 2 & 23 & 13.35 & 4.18 \\
& 1 & 33 & 13.03 & 5.03 \\
Emotional & 2 & 23 & 12.30 & 5.26 \\
& 1 & 33 & 18.48 & 3.13 \\
\hline
\end{tabular}

Note: Group 1 is the control group. Group 2 is the experimental group.

The experimental and control group's pre-test mean scores were within one to four points of one another. See Table 2 for all pre-test mean scores. As shown in Table 3 below, the experimental group scored 
Conklin \& Jairam, Adv. J Social Sci.; Vol. 8, Issue 1, pp: 171-192, 2021

higher than the control group on the post-test total. However, there was no statistical difference between the control group and the experimental group $(t 54)=-0.386, p=.701)$. In fact, the experimental group's posttest $(M=48.70, S D=9.30)$ was only one point higher than the control group $(M=47.76, S D=8.69)$.

Table 3. Results for Independent Samples T-test for Post-Test Scores

\begin{tabular}{lccc}
\hline & $t$ & $d f$ & $p$ \\
\hline Total & -0.39 & 54.00 & 0.70 \\
Social & -0.29 & 54.00 & 0.77 \\
Academic & -1.57 & 54.00 & 0.12 \\
Emotional & 1.85 & 54.00 & 0.07 \\
\hline
\end{tabular}

The experimental group scored higher on the social skills post-test, but not significantly higher $(t(54)=-.029, p=.77)$. The experimental group's social skills post-test $(M=15.30, S D=2.13)$ was less than one point higher than the control group $(M=15.06, S D$ 3.08).

The experimental group did score higher on the academic readiness. However, there was no statistical difference in the scores skills $(t(54)=-1.57, p=.12)$. The experimental group $(M=15.30, S D=$ $4.15)$ only scored nearly two points higher than the control group $(M=13.36, S D=4.79)$ on academic readiness.

Finally, the experimental group scored lower on the post-test than the control group on the emotional regulation skills posttest $(t(54)=1.85, p=.07)$. There was also no significant difference in this test. The experimental group $(M=18.09, S D=2.91)$ scored about one point lower than the control group $(M=19.33, S D=2.15)$ on emotional regulation. Figures 2 and 3 display the means and standard deviations for the post-tests for the control group and experimental group, respectively.

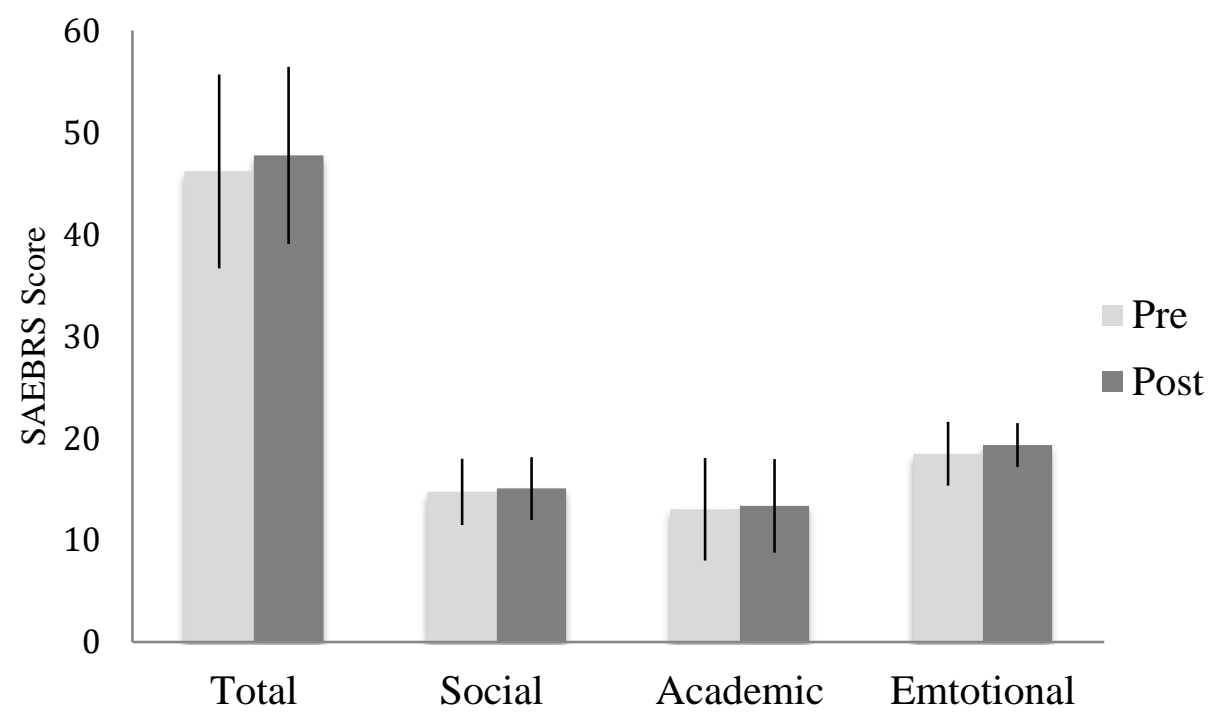

Figure 2: Means and standard deviations of pre-test and post-test SAEBRS scores of the control group. 


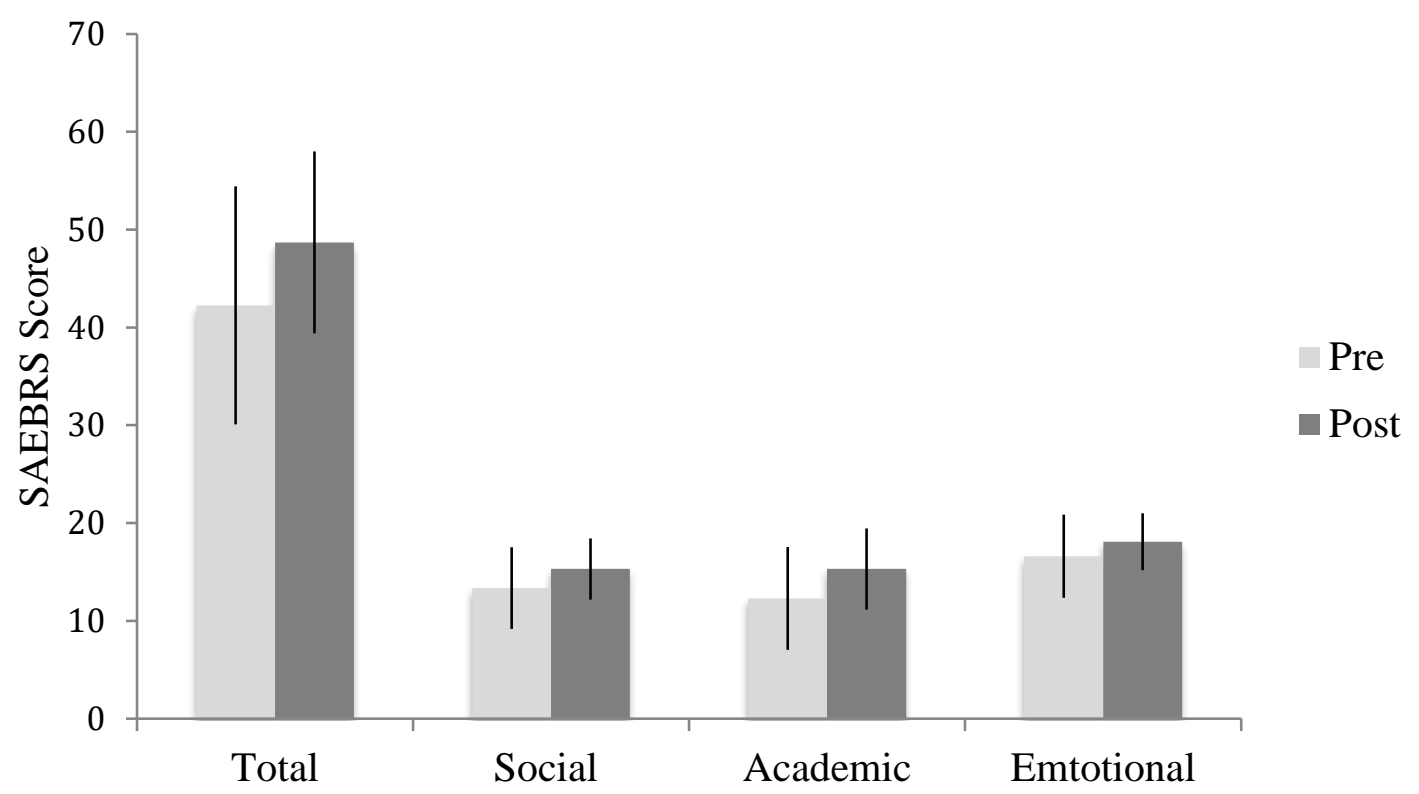

Figure 3: Means and standard deviations of pre-test and post-test SAEBRS scores of the experimental group.

Although results did not show statistical difference on the post-tests between the groups, there were more students in the experimental group who no longer scored at risk after the intervention. At the beginning of the study, there were 13 students at risk in the control group and 12 students who were at risk in the experimental group. At the end of the study, there were 11 students at risk in the control group, and eight students at risk in the experimental group. In addition, there were six students who not at risk when the intervention started and after the intervention they scored at risk. In fact, one of the six students in the control group was at risk in two categories after the intervention occurred. However, there were two students in the experimental group who were not at risk before intervention and scored at risk in one category after the intervention. There were also more students in the experimental group (10) than the control group (7) who reduced the number of categories where they scored at risk.

Overall, findings did not confirm higher scores for the experimental group compared to the control group in total, social, academic or emotional behavior risk. Findings suggest students receiving the Zones of Regulation curriculum did not have higher scores on the behavior risk screener than the students who did not receive the instruction. However, the experimental group improved their score from pre-test to post-test by more points on all four tests. Therefore, the hypothesis that second grade students who received co-taught direct instruction using Zones of Regulation would score higher on the Social, Academic and Emotional Behavior Risk Screener (SAEBRS) than students who do not receive any direct instruction using Zones of Regulation was partially confirmed.

\section{Discussion}

The findings from this study suggest that students who received co-taught direct instruction using Zones of Regulation did not score higher on their social, academic, behavior risk screener (SAEBRS) than students who only received social skills instruction from the school counselor. However, the experimental group improved their score from pre-test to post-test by more points on all four tests. Therefore, the hypothesis was partially confirmed even though there was no statistical significance in the post-test scores.

Although there was no statistical significance in the post-test scores, the experimental group improved their score from pre-test to post-test by more points on all four tests. Students in the experimental group's total score increased four times more points than the control group in the total score. Figure 2 and 
Conklin \& Jairam, Adv. J Social Sci.; Vol. 8, Issue 1, pp: 171-192, 2021

Figure 3 show the comparison of pre- and post-test scores for both the control group and the experimental group. The experimental group also increased their score nearly six times more in social skills, nine times more in the academic readiness and nearly two times more on the emotional regulation than the control group. However, the control group still scored higher than the experimental group at the end of the intervention.

Before the intervention there were 13 students who were at risk in at least one of the four categories. Four students from the experimental group went from at risk to not at risk after the intervention. In the control group there were still 12 students at risk, after the intervention. This was the same number of students who scored at risk before the intervention began. In addition, of the eight students who were still at risk, four of the students reduced their risk in one or more categories. An increased score on the SAEBRS indicates that students who were in the experimental group learned some new strategies. After the intervention students more consistently demonstrated some individual skills noted on the SAEBRS, including how to have appropriate conversations, being prepared for class, completing work, participating in class, and cooperating with their peers. More students demonstrated these skills after the intervention than before the intervention in the experimental group. For example, before the study, there were seven students in the control group and eight students in the experimental group who were not consistently prepared for class. After the study, one student in the control group and six students in the experimental group could now demonstrate this skill. There were similar results for the skills cooperating with peers, completing work, adapting to change, and responding with polite words towards others. There were fewer students in the control group who were demonstrating some skills after the intervention. When reviewing the negative behaviors, temper outbursts and disruptive behavior, on the SAEBRS, students in the control group were no longer having temper outbursts or choosing disruptive behavior often or almost always. However, there were still one to two students who were engaging in these behaviors often or almost always after the intervention.

\subsection{Connections to Past Research}

\subsubsection{PBIS measurements}

Ogulmus \& Vuran (2016) state when a classwide intervention is in place, $80 \%$ of students should respond to the intervention. After the classwide Zones of Regulation intervention, only $65 \%$ of students were not at risk in the experimental group. This could indicate Zones of Regulation may not be an effective classwide intervention since there were still more than $20 \%$ of the students at risk after the intervention.

Unlike Bradshaw et al. (2010) and Nocera et al. (2014), SAEBRS provides information about both positive behaviors learned, as well as a decrease in misbehavior. Since the SAEBRS provides information on both positive and negative behaviors, this may indicate SAEBRS might be a better indicator for behavior than office discipline referrals or suspensions alone.

Similar to Bradshaw et al. (2010), students who had an increased score in social skills indicates they would have less misbehavior that would cause students to have office referrals. If students choose to use a calming strategy rather than choose a disruptive behavior, they would be less likely to receive in an office referral or be suspended. However, similar to Brandt et al. (2014), if a teacher encourages the use of a strategy when a student is misbehaving rather than write an office referral, there is not a decrease in misbehavior, but a change in how to respond to the misbehavior.

\subsubsection{Connections to Co-Teaching}

An increase in the academic readiness skills indicates students were more engaged in their learning because they were more prepared for class, less distracted and completing their work. As Strogilos \& Avramidis (2016) stated, when students are actively engaged, they are less likely to misbehave. An increase in academic readiness means because students were more engaged in their learning, there should be a decrease in misbehaviors. This is confirmed when looking at the behaviors in academic readiness which include working independently, staying on task, participating in class and being prepared for class. SAEBRS 
scores indicate more students were demonstrating these behaviors after the intervention. The increase in social skills may indicate a decrease in misbehavior, which indicates fewer students were arguing and disrupting the learning of others after the intervention.

Murawski \& Hughes (2009) stated that when co-teaching occurs students may be provided with opportunities to have additional teaching if they were not demonstrating a skill or a concept. Students who did not understand the skill after a lesson were provided an additional 15-minute mini-lesson on the same skill. The students who received this additional mini-lesson had an increased SAEBRS score. Providing this additional lesson aligns with Sweigart \& Landrum's (2015) study, where students who were in co-taught classes were more likely to get one to one assistance.

\subsubsection{Connection to Self-Regulation Theory}

Zimmerman's (1990) self-regulation theory explains that self-regulated learners continuously seek strategies so they can be at their best to learn (Zimmerman, 1990; Zimmerman, 2002). Students who were taught the various sensory, calming, thinking and problem-solving strategies should have determined which strategies worked for them to be regulated and not have misbehaviors (Zimmerman, 1990). However, after the intervention eight students were still at risk in the experimental group. Students were not consistently using the strategies taught. Therefore, this intervention contradicts Zimmerman's (1990) theory, with learning social and emotional skills. There were still eight students who were provided the proper strategies but could not determine the best strategy for them to solve their problems consistently as indicated by their at risk score.

Although the experimental group was provided various strategies for problem-solving, calming, and emotional regulation, students did not score significantly higher on the SAEBRS than the control group. The students were not effectively using the strategies they believed worked for them or not using any strategy at all. Students who were still at risk after the intervention could not determine which strategy to use when presented with a stressful situation. They still need support and guidance in choosing the appropriate strategy. If students need to be told which strategies to use to solve problems and regulate their emotions, Zimmerman's (1990) theory is not supported.

Ning \& Downing's (2015) study found that students who were self-regulated learners were statistically more motivated in the classroom. An increased score in academic readiness indicates students who have learned academic readiness skills were more likely to demonstrate behaviors that could motivate them to participate in the classroom. Eighty-seven percent of students were demonstrating academic readiness skills after the intervention compared to $65 \%$ before the intervention began. In the control group, less than $80 \%$ of students were still not demonstrating academic readiness skills after the intervention. So, although Zimmerman's (1990) theory does not seem to be supported when learning social skills or emotional regulation, Zimmerman's (1990) theory may be supported when learning academic readiness skills.

\subsection{Limitations and Recommendations}

\subsubsection{SAEBRS completion}

There were four limitations that need to be considered in this study. The included the implementation duration, co-teaching, and the indicator used. Each of these limitations was considered and potential recommendations for each limitation suggested.

Two different teachers completed the pre- and post-test social, academic, and emotional behavior risk screener (SAEBRS). First grade teachers completed the SAEBRS pre-test in the spring. The intervention occurred at the beginning of second grade, so the second grade teachers completed the posttest. Some post-test results could have been due the intervention, how the two different teachers scored each student, or the students responding a different teacher's approach.

A future recommendation would be to have the same teacher complete the SAEBRS for the pretest and the post-test. The concern about whether the score changed because of the environment or the 
Conklin \& Jairam, Adv. J Social Sci.; Vol. 8, Issue 1, pp: 171-192, 2021

intervention is eliminated when the same person completes the SAEBRS. In addition, the same expectations would be used when complete the SAEBRS for pre- and post-test.

\subsubsection{Short implementation duration}

The nine-week quarter for implementation was too short. The time after the intervention finished and the time students had to show their use of strategies consistently was limited due to the length of the study. The students only had two weeks after the final lesson to demonstrate they were using the skills they had learned.

A potential future recommendation would be to increase the implementation duration between pre-test and post-test, perhaps using an entire school year. This would provide students more time to explore the various coping strategies in natural environments and determine which strategies may work better for them. In addition, a longer duration would provide the students with more time to demonstrate the skills they learned.

\subsubsection{Co-teaching}

This experiment was co-taught. With two class-wide interventions occurring at the same time, the validity of Zones of Regulation is reduced. Therefore, the outcome of this study could be attributed to the co-teaching, Zones of Regulation, or a combination.

A future recommendation would be to teach Zones of Regulation by one teacher rather than cotaught. By eliminating co-teaching, only one class-wide intervention is being used. In addition, the results would better indicate if using the Zones of Regulation intervention alone provides statistically significant results.

\subsubsection{Using only one indicator}

Using the SAEBRS score as the only indicator, did not give provide information about what skills the students may have learned. This study did not address whether students had skills before or after the intervention. Knowing if students understood emotions, could identify their emotional state, or if students already had coping strategies they were using before the intervention began would have been beneficial in determining which lessons each student needed, and which students learned skills because of the intervention. In addition, if the students' behavior improved, their academic scores may have also improved. An academic indicator could also be considered for future research to determine if students decrease in misbehavior, leads to an increase in their academic achievement.

A final recommendation would be to find another indicator that provides information on what the students did or did not learn from receiving Zones of Regulation instruction is recommended. Finding a measure that determines if students know strategies and choose not to use them, know strategies but do not know how to use them, or if they do not know any strategies could provide better information for both teachers and students. Using this measure could determine if students' scores were changed (or not) due to skill deficit (they do not know the skill) or a performance deficit (they know the skill, but are not using it). This information could explain why students may have scored a certain way and provide teachers with potential next steps for students.

\section{Conclusions}

This study discussed the potential of Zones of Regulation curriculum as a class-wide intervention to reduce misbehavior. However, there was no statistical significance in the post-test scores on the SAEBRS. This study did not confirm that teaching Zones of Regulation is an effective class-wide intervention for reducing misbehavior. This study was completed in one classroom in a small Midwestern town in the United States. There were several limitations within this study. However, further research should be done to determine if Zones of Regulation is an effective class-wide intervention. Student misbehavior is still a concern in classrooms today and finding a way to reduce misbehavior is important for 
both students and teachers. Further research should be done to determine if using Zones of Regulation, as a class-wide intervention that will positively affect SAEBRS scores. In addition, other class-wide interventions should be explored to reduce SAEBRS scores. Finding a class-wide intervention to reduce misbehavior in the classroom is important to create an environment where all students can effectively learn.

\section{Appendices}

Appendix A \& B file is available at URL: https://doi.org/10.21467/ajss.8.1.171-192

\section{Competing Interests}

There were no competing interests.

\section{How to Cite this Article:}

Conklin, M., \& Jairam, D. (2021). The Effects of Co-Teaching Zones of Regulation on Elementary Students' Social, Emotional, and Academic Risk Behaviors. Advanced Journal of Social Science, 8(1), 171-192. https://doi.org/10.21467/ajss.8.1.171-192

\section{References}

Algozzine, K., Christian, C., Marr, M. B., McClanahan, T., \& White, R. (2008). Demography of problem behavior in elementary schools. Exceptionality, 16, 93-104. https://doi.org/10.1080/09362830801981369

Alter, P., Walker, J., \& Landers, E. (2013). Teachers' perceptions of students' challenging behavior and the impact of teacher demographics. Education and Treatment of Children, 36(4), 51-69. http://dx.doi.org/10.1353/etc.2013.0040

Arens, A.K., Morin, A. J. S., \& Waterman, R. (2015). Relations between classroom disciplinary problems and student motivation: Achievement as a potential mediator? Learning and Instruction, 39, 184-193. https://doi.org/10.1016/j.learninstruc.2015.07.001

Barron, T. L., Pinter, H. H., \& Winter, K. K. (2019). Supporting student and pre service teacher successes through co-teaching. Theory and Practice in Rural Education, 9(2), 65-78. https://doi.org/10.3776/tpre.2019.v9n2p65-78

Boyd, M. P., \& Smyntek-Gworek, S. (2012). Morning meeting in a third grade classroom:Literacy and learning. Journal of Classroom Interaction, 47(2), 4-12. Retrieved March 18, 2019, from http://www.jstor.org/stable/43858876

Brackett, M. A., Reyes, M. R., Rivers, S. E., Elbertson, N. A., \& Salovey, P. (2011). Classroom emotional climate, teacher affiliation and student conduct. Journal of Classroom Interaction, 46(1), 27-36.

Bradshaw, C. P., Mitchell, M. M., \& Leaf, P. J. (2010). Examining the effects of schoolwide positive behavioral interventions and supports on student outcomes: Results from a randomized controlled effectiveness trial in elementary schools. Journal of Positive Behavior Interventions, 12(3), 133-148. https://doi.org/10.1177/1098300709334798

Brandt, R. C., Chitiyo, M., \& May, M. E. (2014). Measures used in assessing outcomes of school-wide positive behavior support. Journal of Research in Special Educational Needs, 14(4), 229-238. https://doi.org/10.1111/j.1471-3802.2012.01260.x

Bru, E. (2009). Academic outcomes in school classes with markedly disruptive pupils. School Psychology of Education, 12, 461-479. https://doi.org/10.1007/s11218-009-9095-1

Chitiyo, J. (2017). Challenges to the use of co-teaching by teachers. International Journal of Whole Schooling, 13(3), 55-66.

Cochran, J. L., Gibbons, M. M., Spurgeon, S., \& Cochran, N. H. (2014). Challenges in educating students with highly disruptive behaviors in a large, high poverty, elementary school. The Journal of At Risk Issues, 18(2), 1-10.

Counts, J., Randall, K. N., Ryan, J. B., \& Katsiyannis, A. (2018). School resource officers in public schools: A national review. Education and Treatment of Children, 41(4), 405-530.

Dalgic, G., \& Bayhan, G. (2014). A meta-analysis: Student misbehaviors that affect classroom management. Cypriot Journal of Educational Sciences, 9(2), 101-116.

Department for Education (2012) Pupil Behaviour In Schools In England. (Research Report DFE-RR218). England: Education Standards Analysis and Research Division.

Ducharme, J. M. \& Shecter, C. (2011). Bridging the gap between clinical and classroom intervention: Keystone approaches for students with challenging behaviors. School Psychology Review, 40(2), 257-274. https://doi.org/10.1080/02796015.2011.12087716

Duncan, R. J., Schmitt, S. A., Burke, M., \& McClelland, M. M. (2017). Combining a kindergarten readiness summer program with a selfregulation intervention improves school readiness. Early Childhood Research Quarterly, 42, 291-300. https://doi.org/ 10.1016/j.ecresq.2017.10.012

Fabelo, T., Thompson, M. D., Plotkin, M. P., Carmichael, D., Marchbanks, M. P., \& Booth, E. A. (2011). Breaking Schools' Rules: A Statewide Study of How School Discipline Relates to Students' Success and Juvenile Justice Involvement. New York, NY: Council of State Governments Justice Center.

Fallon, L. M., McCarthy, S. R., \& Sanetti, L. M. H. (2014). School-wide positive behavior supports (SWPBS) in the classroom: Assessing perceived challenges to consistent implementation in Connecticut schools. Education and Treatment of Children, 37(1), 1-24.

Finn, J. D., Fish, R. M., \& Scott, L. A. (2008). Educational sequelae of high school misbehavior. The Journal of Educational Research, 101(5), 259-274. https://doi.org/10.3200/ JOER.101.5.259-274

Friend, M. (2008). Co-Teaching: A Simple Solution That Isn't Simple After All. Journal of Curriculum and Instruction, 2(2), 9-19. https://doi.org/10.3776/joci.2008.v2n2p9-19

Gardner, C. (2012). Morning meeting an science-A winning combination. Science and Children, 50(1), 60-64. 
Conklin \& Jairam, Adv. J Social Sci.; Vol. 8, Issue 1, pp: 171-192, 2021

Hang, Q. \& Rabren, K. (2009). The examination of co-teaching: Perspectives and efficacy indicators. Remedial and Special Education 30(5), 259-268. https://doi.org/ 10.1177/0741932508321018

Harrison, J. R., Vannest, K., Davis, J., \& Reynolds, C. (2012). Common problem behaviors in children and adolescents in general education classrooms in the United States. Journal of Emotional and Behavioral Disorders, 20(1), 55-64. https://doi.org/ $10.1177 / 1063426611421157$

Hayling, C. C., Cook, C., Gresham, F. M., State, T., \& Kern, L. (2008). An analysis of the status and stability of the behaviors of students with emotional and behavioral difficulties. Journal of Behavior Education, 17, 24-42. https://doi.org/10.1007/s10864-007-9059-5

Horner, R. H., Sugai, G., \& Anderson, C. M. (2010). Examining the evidence base for school wide positive behavior supports. Focus on Exceptional Children, 42(8), 1-12.

House of Commons Education Committee. (2011). Behaviour and Discipline in Schools: First Report of Session 2010-11. London: The Stationary Office.

Jackson, K. M., Willis, K., Giles, L., Lastrapes, R. E., \& Mooney, P. (2017). How to meaningfully incorporate co-teaching into programs for middle school students with emotional and behavioral disorders. Beyond Behavior 26(1), 11-18. https://doi.org/ $10.1177 / 1074295617694408$

Kilgus, S. P. (2014). Social Academic, and Emotional Behavior Risk Screener (SAEBRS) Scoring Guide.

Kilgus, S. P., Eklund, K., von der Embse, N. P., Taylor, C. N., \& Sims, W. A. (2016). Psychometric defensibility of social, academic and emotional behavior risk screener (SAEBRS) teacher rating scale and multiple gating procedure within elementary and middle school samples. Journal of School Psychology, 58, 21-39. https://doi.org/10.1016/j.jsp.2016.07.001

King-Sears, M. E., Brawand, A. E., Jenkins, M. C., \& Preston-Smith, S. (2014). Co-teaching perspectives from secondary science co-teachers and their students with disabilities. Journal of Science Teacher Education, 25, 651-680. https://doi.org/10.1007/s10972-014-9391-2

Kuypers, L. M. (2011). The Zones of Regulation: A Curriculum Designed to Foster Self Regulation and Emotional Control. Santa Clara, CA: Think Social Publishing, Inc.

Liew, J. (2011). Effortful control, executive functions, and education: Bringing self-regulatory and social-emotional competencies to the table. Child Development Perspectives, 6(2), 105-111. https://doi.org/10.1111/j.1750-8606.2011.00196.x

Mallett, C. A. (2016). The School to Prison Pipeline: A Comprehensive Assessment. New York, NY: Springer Publishing Company, LLC.

Martinez, A., McMahon, S. D., Coker, C., \& Keys, C. B. (2016). Teacher behavioral practices:Relations to student risk behaviors, learning barriers, and school climate. Psychology in the Schools, 53(8), 817-830. https://doi.org/10.1002/pits.21946

Moffitt, T. E., Arseneault, L., Belsky, D., Dickson, N., Hancox, R. J., Harrington, H., Caspi, A. (2011). A gradient of childhood self-control predicts health, wealth, and public safety. PNAS 108(7), 2693-2698. https://doi.org/10.1073/pnas.1010076108

Murawski, W. W. \& Hughes, C. E. (2009). Response to intervention, collaboration, and co-teaching: A logical combination for successful systematic change. Preventing School Failure, 53(4), 267-277. https://doi.org/10.3200/PSFL.53.4.267-277

Musu-Gillette, L., Zhang, A., Wang, K., Zhang, J., Kemp, J., Diliberti, M., and Oudekerk, B.A. (2018). Indicators of School Crime and Safety: 2017 (NCES 2018-036/NCJ 251413). National Center for Education Statistics. Wahsington D.C.: U.S. Department of Education, and Bureau of Justice Statistics, Office of Justice Programs, U.S. Department of Justice.

Ning, H. K. \& Downing, K. (2015). A latent profile analysis of university students'self regulated learning strategies. Studies in Higher Education, 40(7), 1328-1346. https://doi.org/10.1080/03075079.2014.880832

Nocera, E. J., Whitbread, K. M., \& Nocera, G. P. (2014). Impact of school-wide positive behavior supports on student behavior in the middle grades. Research in Middle Level Education, 37(8), 1-14

Ogulmus, K. \& Vuran, S. (2016). Schoolwide positive behavioral interventions and support practices: Review of studies in the journal of positive behavior interventions. Education Sciences: Theory and Practice, 16(5), 1693-1710. https://doi.org/ 10.12738/estp.2016.5.0264

Perez, L. M. (2011). Teaching emotional self-awareness through inquiry-based education. Early Childhood Research and Practice. 13(2), 18

Ratcliff, N. J., Jones, C. R., Costner, R. H., Savage-Davis, E., \& Hunt, G. H. (2010). The elephant in the classroom: The impact of misbehavior on classroom climate. Education, 131(2), 306-314.

Raver, C. C., Jones, S. M., Li-Grining, C., Zhai, F., Bub, K., \& Pressler, E. (2011). CSRP's Impact on low-income preschoolers' preacademic skills: Self-regulation as a mediating mechanism. Child Development, 82(1), 362-278. https://doi.org/10.1111/j.14678624.2010.01561.x

Robers, S., Kemp, J., Rathbun, A., Morgan, R. E., \& Snyder, T. D. (2014) Indicators of School Crime and Safety: 2013. Washington, D.C.: National Center for Education Statistics, U.S. Department of Education, and Bureau of Justice Statistics, Office of Justice Programs, U.S. Department of Justice.

Romi, S. Lewis, R., \& Salkovsky, M. (2015). Exclusion as a way of promoting student responsibility: Does the kind of misbehavior matter? The Journal of Educational Research, 108, 305-317. http://dx.doi.org/10.1080/00220671.2014.886177

Soave, R. \& Koteskey, T. (2017, March). Why are they putting kids in cuffs? Reason Magazine, 48(10), 46-53. Retrieved from: https://reason.com/2017/01/24/why-are-cops-putting-kids-in-c/

Spaulding, S. A., Irvin, L. K., Horner, R. H., May, S. L., Emeldi, M., Tobin, T. J., \& Sugai, G. (2010). Schoolwide social-behavioral climate, student problem behavior, and related administrative decisions. Journal of Positive Behavior Interventions, 12(2), 69-85. https://doi.org/10.1177/1098300708329011

Strogilos, V., \& Avramidis, E. (2016). Teaching experiences of students with special educational needs in co-taught and non-co-taught classes. Journal of Research in Special Education Needs, 16(1), 24-33. https://doi.org/10.1111/1471-3802.12052

Sweigart, C. A. \& Landrum, T. J. (2015). The impact of number of adults on instruction: Implications for co-teaching. Preventing School Failure, 59(1), 22-29. https://doi.org/10.1080/1045988X.2014.919139

Tyre, A. D. \& Feuerborn, L. L. (2017). The minority report: The concerns of staff opposed to schoolwide positive behavior interventions and supports in their schools. Journal of Educational and Psychological Consultation, 27(2), 145-172. https://doi.org/ $10.1080 / 10474412.2016 .1235977$ 
The Effects of Co-Teacbing Zones of Regulation on Elementary Students' Social, Emotional, and Academic Risk Behaviors

Woltering, S., \& Shi, Q. (2016). On the neuroscience of self-regulation in children with disruptive behavior problems: implications for education. Review of Education Research, 86(4), 1085-1110. https://doi.org/10.3102/0034654316673722

Wyman, P. A., Cross, W., Brown, C. H., Yu, Q., Tu, X., \& Eberly, S. (2010). Intervention to strengthen emotional self-regulation in children with emerging metnal health problems: Proximal impact on school behavior. Journal of Abnormal Child Psychology, 38(5), 707-720. doi: 10.1007/s10802-010-9398-x

Zimmerman, B. J. (1990). Self-regulated learning and academic achievement: An overview. Educational Psychologist, 25(1), 3-17. https://doi.org/10.1207/s15326985ep2501_2

Zimmerman, B. J. (2002). Becoming a self-regulated learner: An overview. Theory into Practice, 41(2), 64-70. https://doi.org/10.1207/s15430421tip4102_2

Zimmerman, B. J. \& Martinez-Pons, M. (1986). Development of a structured interview for assessing student use of self-regulated learning strategies. American Educational Research Journal, 23(4), 614-628. https://doi.org/10.3102/00028312023004614

Publish your research article in AIJR journals-

$\checkmark \quad$ Online Submission and Tracking

$\checkmark$ Peer-Reviewed

$\checkmark \quad$ Rapid decision

$\checkmark \quad$ Immediate Publication after acceptance

$\checkmark \quad$ Articles freely available online

$\checkmark \quad$ Retain full copyright of your article.

Submit your article at journals.aij.org
Publish your books with AIJR publisher-

$\checkmark \quad$ Publish with ISBN and DOI.

$\checkmark$ Publish Thesis/Dissertation as Monograph.

$\checkmark$ Publish Book Monograph.

$\checkmark$ Publish Edited Volume/ Book.

$\checkmark$ Publish Conference Proceedings

$\checkmark \quad$ Retain full copyright of your books.

Submit your manuscript at books.aijr.org 